\title{
Experimental Study of Laser Cladding Methods on Water Erosion Resistance to Low Pressure Blades Materials of Steam Turbine
}

\author{
Di Zhang, ${ }^{1}$ Pengfei Zhao, ${ }^{1}$ Wei Zhao, ${ }^{2}$ Yaoyuan Luo, ${ }^{2}$ and Yonghui Xie ${ }^{2}$ \\ ${ }^{1}$ Key Laboratory of Thermal Fluid Science and Engineering, Ministry of Education, School of Energy and Power Engineering, \\ Xian Jiaotong University, Xian, Shaanxi 710049, China \\ ${ }^{2}$ School of Energy and Power Engineering, Xian Jiaotong University, Xian, Shaanxi 710049, China \\ Correspondence should be addressed to Yonghui Xie; yhxie@mail.xjtu.edu.cn
}

Received 24 February 2014; Accepted 29 April 2014; Published 25 May 2014

Academic Editor: Wanguo Zheng

Copyright (C) 2014 Di Zhang et al. This is an open access article distributed under the Creative Commons Attribution License, which permits unrestricted use, distribution, and reproduction in any medium, provided the original work is properly cited.

\begin{abstract}
An experimental apparatus was built to study the effects of liquid-solid impact on laser cladding processing specimens of 17-4PH stainless steel material in the present investigation. Then the result of specimens without laser surface process was compared. The impact effect on the specimens was observed using the three-dimensional digital microscope. The depth of laser cladding and substrate material caused by liquid droplet impact was studied in detail and measured. The accuracy and reliability of the experimental system and computing methods were also verified. The depth of the impact area of laser cladding specimens was distributed in the range of $0.5-1.5 \mu \mathrm{m}$ while the 17-4PH group was distributed in the range of $2.5-3.5 \mu \mathrm{m}$. In contrast with specimens without laser surface processing, the material processed by laser cladding has significantly higher resistance to water erosion.
\end{abstract}

\section{Introduction}

In the condensing steam turbines of nuclear power plants and thermal power units, wet steam flow causes the erosion of the last stage blades and may cause considerable damage to the turbine. The reliability of turbines decreases over time and makes their lifetime shorter because of water erosion [13]. A number of experimental and theoretical investigations have been carried out to find a solution for controlling and curbing the bad effects of erosion. The antierosion measures can be divided into passive and objective methods. Varieties of dehumidification equipment have been adopted such as stator blade suction devices and humidity-removing stages to reduce the amount of droplets actively. Passive methods mainly include choosing the erosion resistance materials, strengthening the bucket exit edge, and using the protective coating to ensure the blades against eroding by water during normal working life, even after long-term water erosion from harming blade. Passive protection is the main method currently used by the world's major companies [4-8].
17-4PH material has been widely used in the manufacture of LP (low pressure) blades of steam turbine. And laser hardening of the last stage blades of steam turbine has been carried out to reduce the water erosion. As a passive protection technology, laser cladding surface treatment method is a relatively new technology [9-11]. In this paper, the dynamic stress response of laser cladding and ordinary $17-4 \mathrm{PH}$ specimens impacted by liquid droplet were investigated. The depth of pits caused by liquid droplet impact was measured, and the dimensions of damage area were recorded and analyzed statistically. It will provide the basis reference about surface treatment processing of last stage blades of steam turbine.

\section{Experimental Test System}

In this test system, a high speed impactor was developed. High pressure gas was employed to push piston and projectile supplied by detonating explosive in Type NS-603 Nail Ejector. Then a nylon rod is accelerated by the piston. The process of 


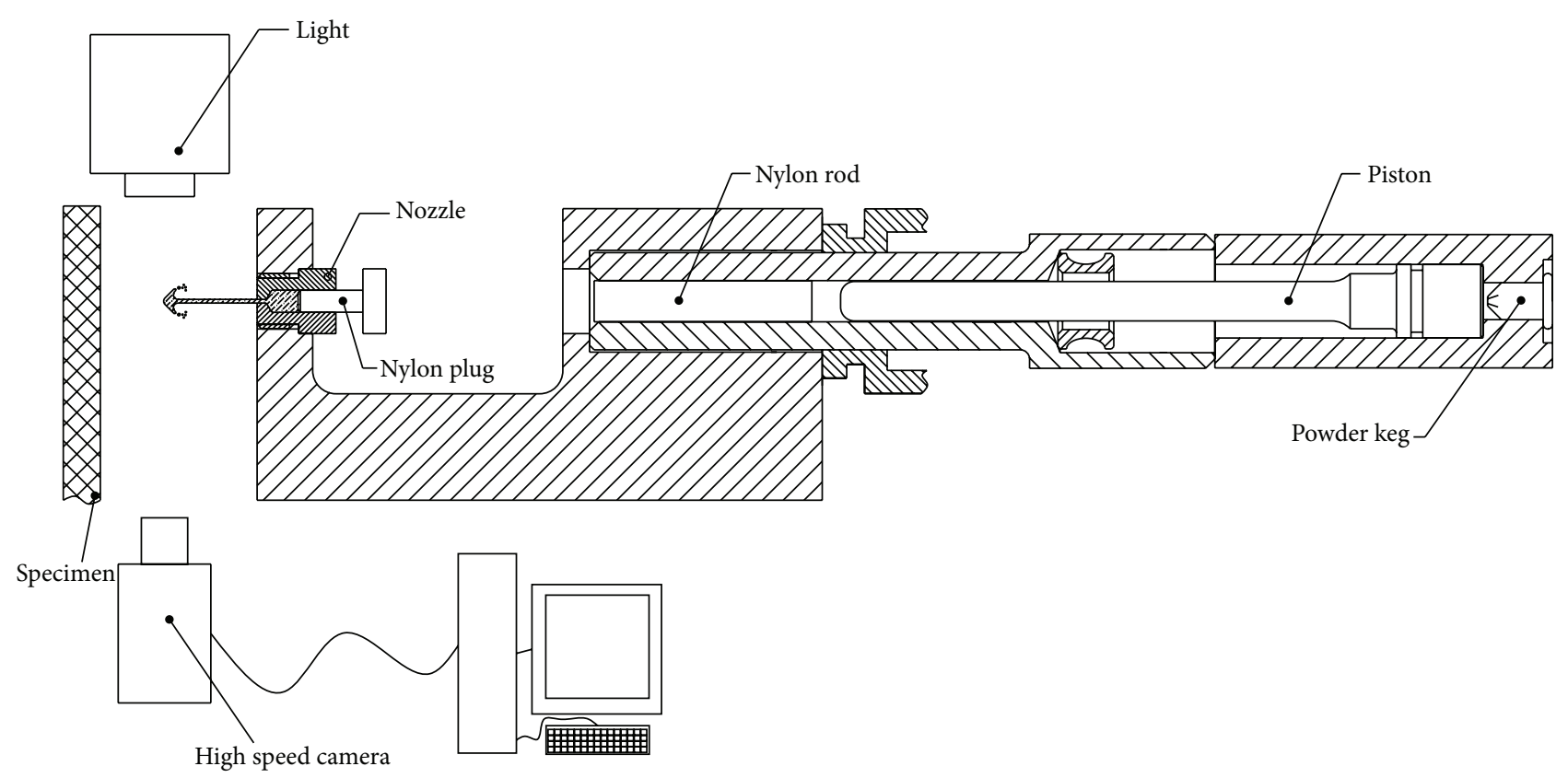

FIGURE 1: Schematic diagram of the test system.

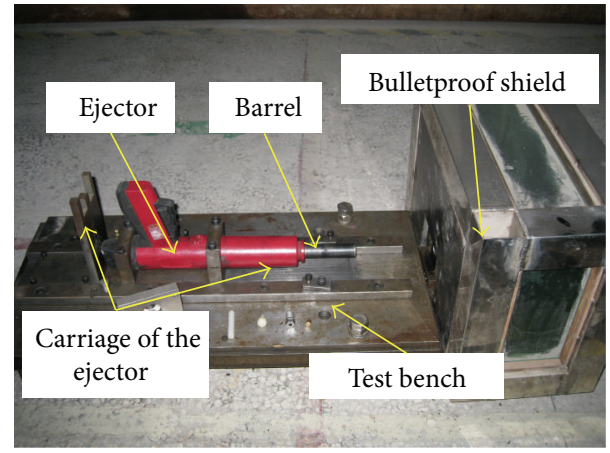

FIGURE 2: The photo of the experimental setup.

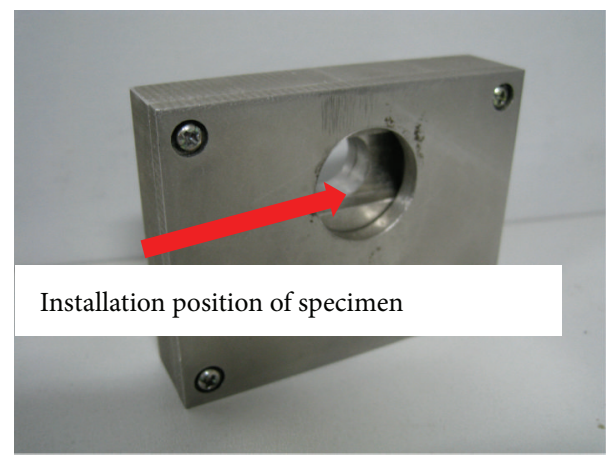

FIGURE 3: Specimen holder.

high speed impact between nylon rod and nylon plug results in high speed water droplets. The shape and location of water were obtained via high speed camera MEMRECAM FX-K3 with the speed of 104 frames/s.

According to the droplets velocity calibration, the speed of droplets produced by the test system can reach up to $600 \mathrm{~m} / \mathrm{s}$ or more. The dimension of explosive chamber varies
TABLE 1: Material parameters of solid.

\begin{tabular}{lc}
\hline Material parameter & Value \\
\hline Mass density & $7820 \mathrm{~kg} / \mathrm{m}^{3}$ \\
Tensile strength & $1000 \mathrm{MPa}$ \\
Poisson's ratio & 0.272 \\
Yield strength & $945 \mathrm{MPa}$ \\
Tangent modulus & $7.74 \mathrm{GPa}$ \\
\hline
\end{tabular}

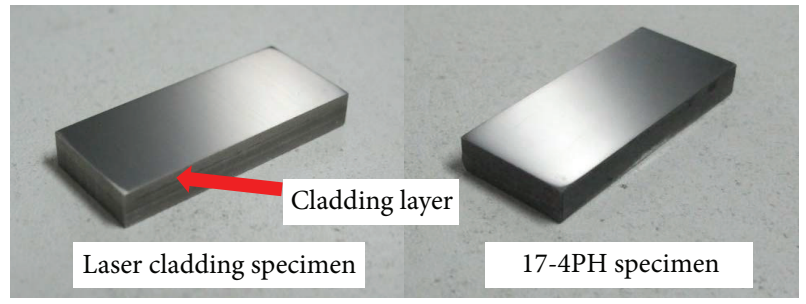

FIgURE 4: Photo of the specimens.

with piston positions to obtain different velocity. Figures 1 and 2 show the photo and the schematic diagram of the test system. Figure 3 is the specimen holder.

During the test, the nylon rod was placed in the barrel, and the nylon plug was inserted in the nozzle inlet section. To ensure the sealing of the nozzle chamber, the nylon plug shall be applied with a certain number of Vaseline. The water was injected via a microsyringe from another side of the nozzle. Then the specimen was installed to the striking position together with the fixture. The ejector and its carriage were then fixed on the test bench by two bolts on both sides of the nail. The last step of the preparation work was covering the impact area with a bulletproof shield. After impact, the specimen should be cleaned and preserved before further analysis.

In this paper, the base material of laser cladding is $17-4 \mathrm{PH}$ stainless steel, whose parameters are listed in Table 1. 


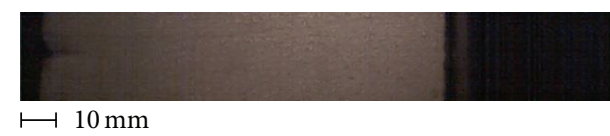

(a)

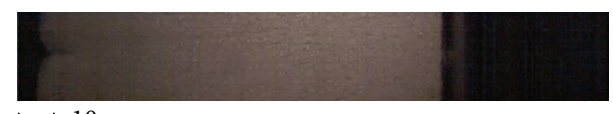

(b)

FIgURE 5: Two pictures taken at intervals of $10^{-4} \mathrm{~s}$.

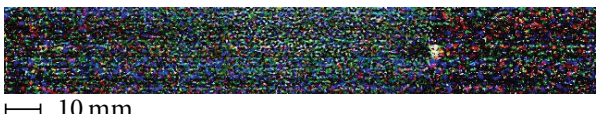

FIGURE 6: 30 times sharpening of the differential chart.

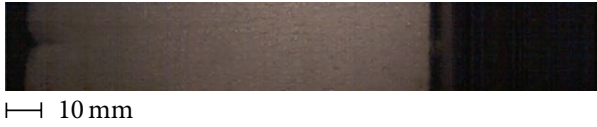

(a)

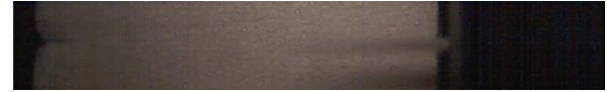

(b)

Figure 7: Two pictures taken at intervals of $10^{-4} \mathrm{~s}$

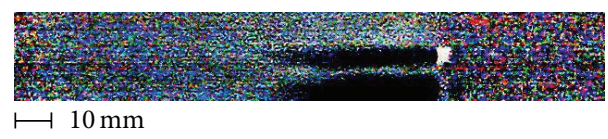

(a)

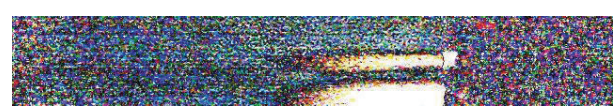

$\longmapsto 10 \mathrm{~mm}$

(b)

FiguRE 8: Effects of 30 times sharpening in Figure 7.

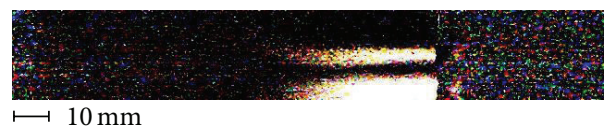

FIGURE 9: Picture for statistical results of jet frontier.

The material samples were processed into cuboids with the dimension of $35 \mathrm{~mm} \times 15 \mathrm{~mm} \times 5 \mathrm{~mm}$. Since the surface treatment layer on the specimen is relatively thin, only a slight degree of surface polishing has been carried out. Then the specimens with the cotton ball dipped in ethanol were cleaned before and after the impact test. Figure 4 shows the specimens before the test. During the test, they were installed on the special fixture which fixed vertically $10 \mathrm{~mm}$ away from the nozzle.

\section{Method of Calculating Droplets Velocity}

The MEMRECAM FX K3 high speed camera was used to capture the motion state of the droplets. The boundary of droplets captured by the camera is not very clear. However, knowing the position of jet frontier in two pictures is the only way to obtain the droplets velocity. So it is necessary to process the high speed photographs.

Firstly, the background of two adjacent pictures is almost the same. The only difference is the shape and the position of the jet.

On test data with 104 frames, the resolving power of the instrument is $640 \times 96$. For each processed picture, the obtained RGB image is actually a $M \times N \times 3$ matrix. Each point $(x, y)$ in the two-dimensional picture and its color can be expressed as a color vector composed of RGB components:

$$
C_{(x, y)}=(r, g, b) .
$$

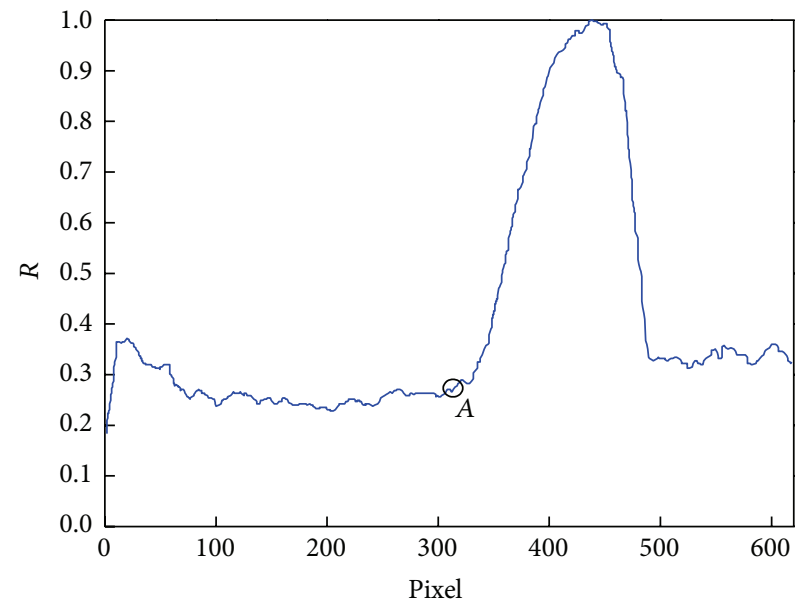

FIGURE 10: Distribution of the filtered $R$ with the horizontal position of the image.

From the difference between the pixels coding of the binary image of the block of present frame and that of previous frame, the following can be obtained:

$$
\Delta C_{(x, y)}= \begin{cases}C_{(x, y)}^{(n+1)}-C_{(x, y)}^{(n)}, & C_{(x, y)}^{(n+1)}-C_{(x, y)}^{(n)}>0, \\ 0, & C_{(x, y)}^{(n+1)}-C_{(x, y)}^{(n)} \leq 0 .\end{cases}
$$




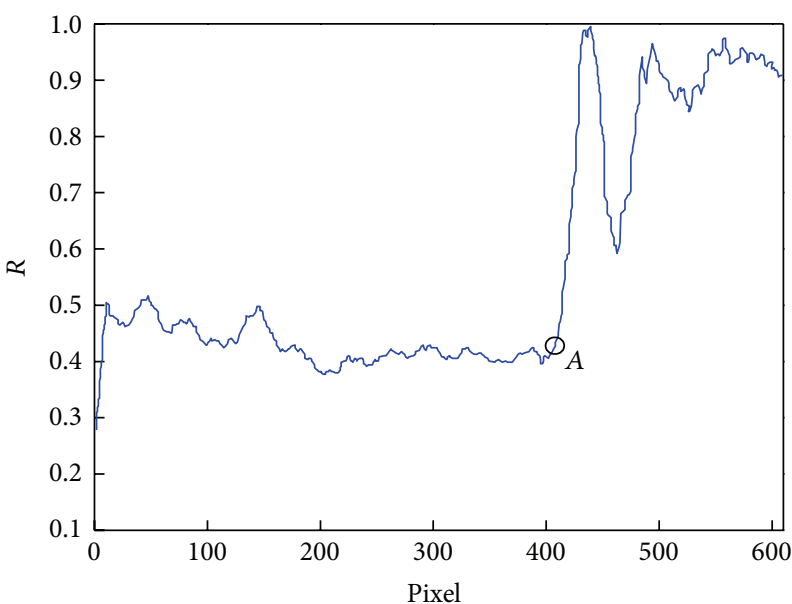

(a)

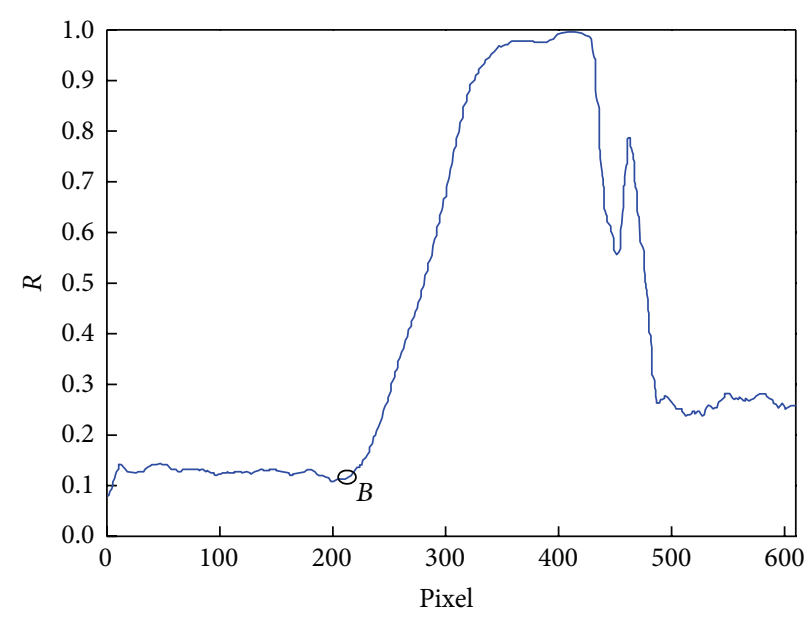

(b)

FIGURE 11: Distribution of the filtered $R$ with the horizontal position of the image.

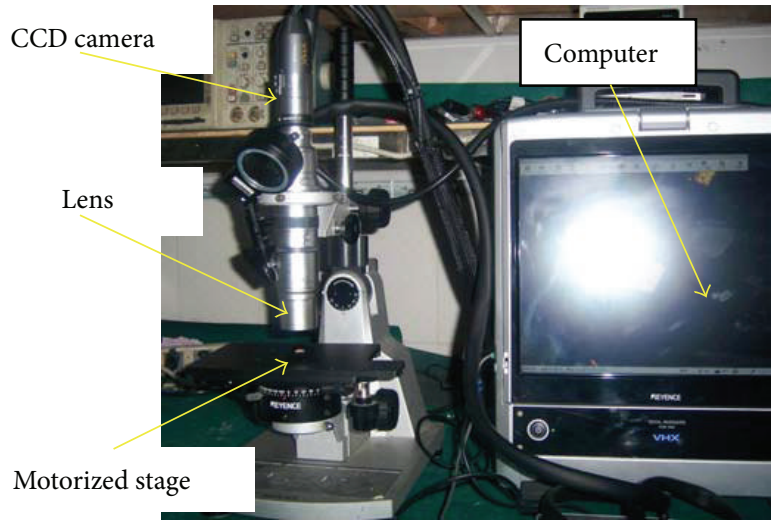

FIgURE 12: The VHX-600 digital microscope.

Thus an image formed by color difference of the two pictures emerges. Figure 6 shows the two pictures taken at intervals of $10^{-4} \mathrm{~s}$.

This paper performed image sharpening to the differential chart. Figure 6 is the difference between Figures 5(a) and 5 (b) after 30 times sharpening. It is clear that a region emerges where white color centered.

To get the velocity, the picture at next frame of Figure 5(b) should be introduced, which is shown in Figure 7(b). For better comparison, frame of Figure 5(b) is also shown in Figure 7, that is, Figure 7(a).

In order to reduce the noise signal, a figure of the difference of their absolute values is obtained by using the following methods:

$$
|\Delta| C_{(x, y)}=\left|C_{(x, y)}^{(n+1)}-C_{(x, y)}^{(n)}\right|
$$

A vector $R_{(x, y)}$ generated by the subtraction of $\Delta C_{(x, y)}$ and $|\Delta| C_{(x, y)}$ will reduce the noise in the environment to its minimum level.
And the differential chart (see Figure 9) generated from Figure 8 can be in almost perfect profile.

In order to obtain the position of the jet frontier, further statistical processing of the image is needed. A real matrix $R$ is generated from the 2-norm of three elements of the $R(x, y)$ vector by taking $x$ as the column and $y$ as the row. Figure 10 can be obtained by summing each column of the matrix and normalizing the results.

In order to obtain the relationship between the pixel and the actual size, we also require a conversion unit of length. For this reason, a ruler placed in the same position with the jet was photographed with the same resolution.

From Figures 5-9, we learn that the actual $1 \mathrm{~mm}$ occupies 3.6 pixels length. Thus the velocity of the jet can be calculated easily. Taking Figure 11(a) and the adjacent frame of Figure 11(b) as example, their lateral attitudes are, respectively, 433 and 219.

According to the " 3.6 pixels $=1 \mathrm{~mm}$ " conclusion, the initial droplets velocity used in this experiment is

$$
v_{\text {jet }}=\frac{433-219}{3.6} \times \frac{10^{-3}}{10^{-4}}=594 \mathrm{~m} / \mathrm{s} .
$$

The liquid droplets velocity in the air is gradually reduced with the distance and the designed distance between the specimen and the export is only $10 \mathrm{~mm}$, so it is reliable to estimate $600 \mathrm{~m} / \mathrm{s}$ as the droplets velocity.

\section{Experimental Results and Analysis}

The VHX-600 digital microscope (see Figure 12) is used to measure the three-dimensional profile of the sample before and after high speed liquid impact. Through an advanced zoom lens design and integrated setup, the microscopes are able to achieve a 20-time greater depth-of-field comparing with a typical optical microscope. This allows specimens with large variations in surface topography to be focused and accurately observed in a single image. 


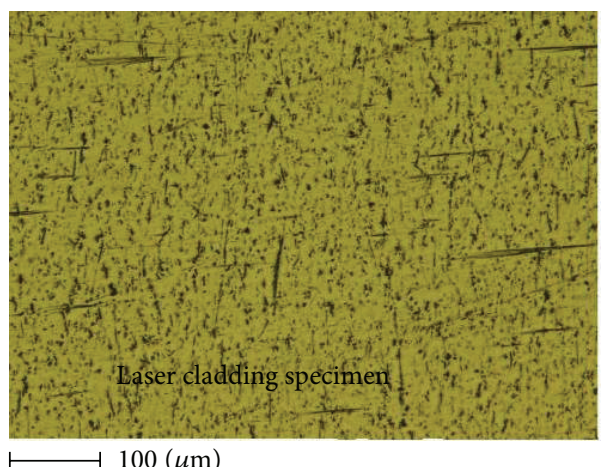

(a)

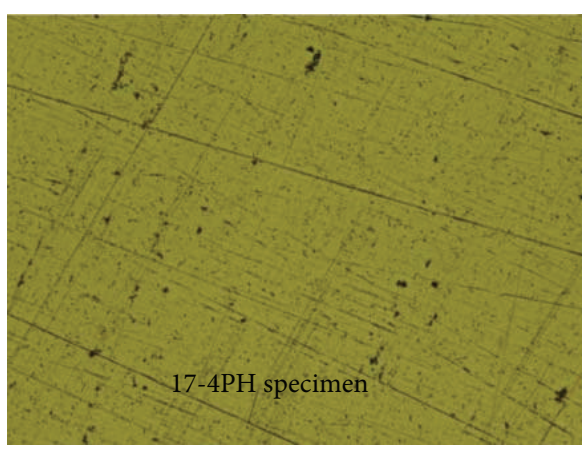

(b)

FIGURE 13: 500 times magnification of two specimens after impact.

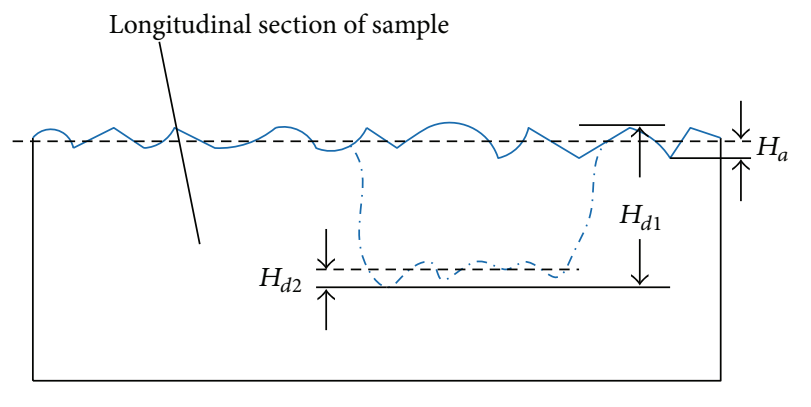

— Surface topography before impact

-..- Pits after impact

FIGURE 14: Schematic diagram of principle of measuring the impact pits.

During the observation, vertical movement of the microscope lens is controlled by a computer. Current image captured by the lens after a tiny step length is transferred into the computer through high resolution CCD to process. The scene is identified from the focal length plane of the image by a program. When the lens driven by the step motor moves to a preset height, the focal length plane of the microscope just fall the scope of the field with certain depth to observe. The images obtained on the focal length plane of all steps are composted to get the three-dimensional surface of the corresponding area.

Figure 13 shows 500-time magnification of two specimens after impact. Three-dimensional scanning of the impact area is shown in Figure 15. In order to prevent the surface treatment layer from wearing away, the specimens were polished slightly. Therefore, it is difficult to distinguish the impact area visually. However, the phenomenon in the depth cloud map of specimens (see Figure 15) appears to be very obvious. The damage pattern observed after liquid impact on the specimen is typically a series of discrete cracks around or deviates from the central zone.

The presence of surface roughness cannot be ignored whatever the extent of polishing. Thus the surface roughness must be considered when calculating the pit depth. Figure 14 is the schematic diagram of principle of measuring the impact pits. It describes the changes in the surface morphology of the sample before and after impact intuitively. Before the test, the surface profile from top to the bottom in the height direction of each specimen is measured for 3 times. Then we obtain their integral mean values and make them as average height $\left(H_{a}\right)$ of materials before impact.

Use $H_{d}$ which represents the height difference of the impact zone. Considering that the impact of droplets is a region rather than a point, we need to obtain the average height of the impact zone $\left(H_{d 2}\right)$. Then $H_{d}$ can be obtained by subtracting $H_{d 2}$ from the overall maximum height difference $\left(H_{d 1}\right)$ as shown in

$$
H_{d}=H_{d 1}-H_{d 2} .
$$

At last, the average pit depth can be obtained by subtracting $H_{a}$ from $H_{d}$ :

$$
D=H_{d}-H_{a}=H_{d 1}-H_{d 2}-H_{a} .
$$

$H_{a}$ is introduced to avoid the effects of surface roughness and has already been obtained before the test. $H_{d 1}$ is the maximum value in the depth cloud map of specimens impacted by high speed droplets. $H_{d 2}$ can be obtained by calculating the mean value of selected numbers from the surface elevation curves of specimens after impact. Thus, the relative accurate impact pit depth can be obtained by the abovementioned equations.

The impact region is relatively small and impurities exist in the steel itself, which may affect the results. In order to make the results more convincing, each group includes 6 specimens.

The region of impact can be distinguished by observing the three-dimensional scanning area. For the laser cladding specimens, the maximum relative depth of the specimens after being impacted is $6.4 \mu \mathrm{m}$ with the minimum depth being $4.1 \mu \mathrm{m}$. Since the surface is not polished to a mirror effect and the droplets are distracted before impact, the maximum depth value is not worth too much. In order to prove our judgment, amplitude distribution curves of visual field after impact should be obtained before comparing the 


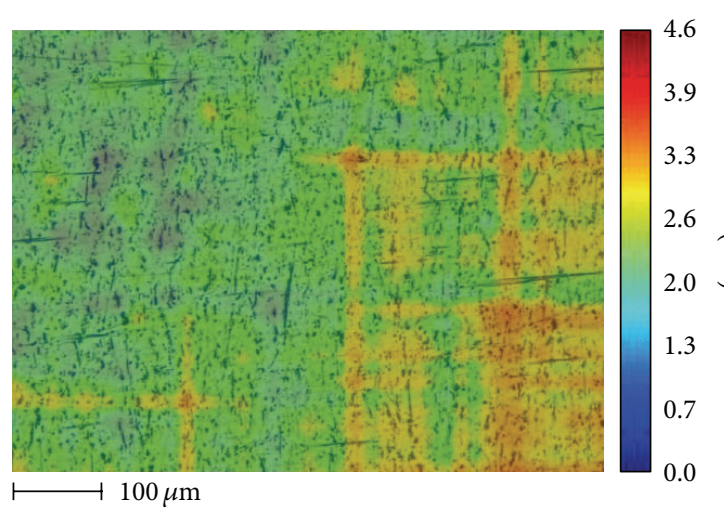

(a)

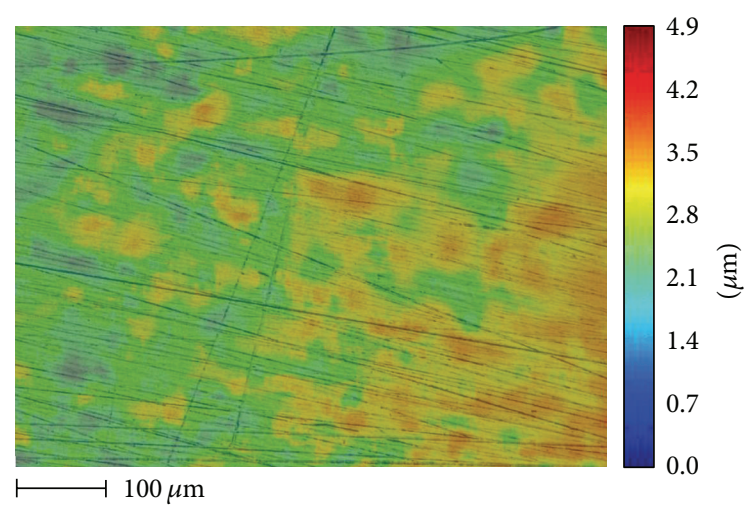

(c)

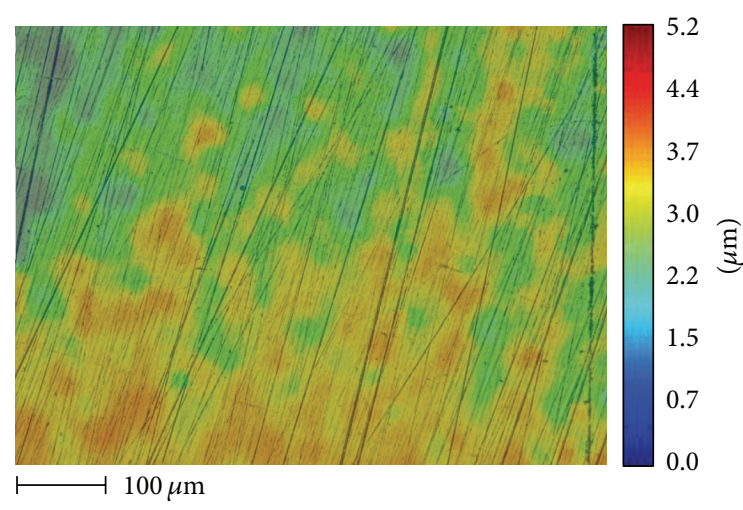

(e)

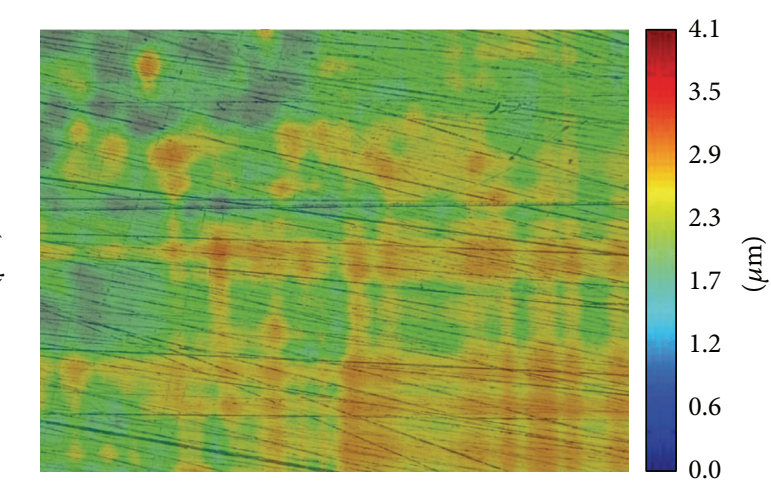

(b)

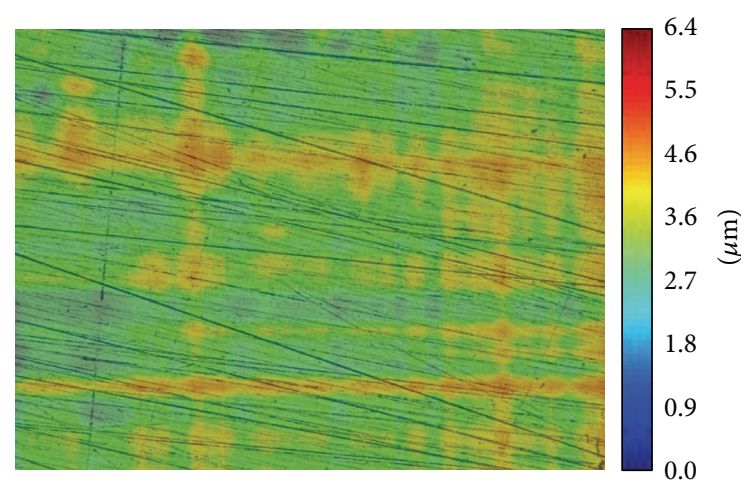

(d)

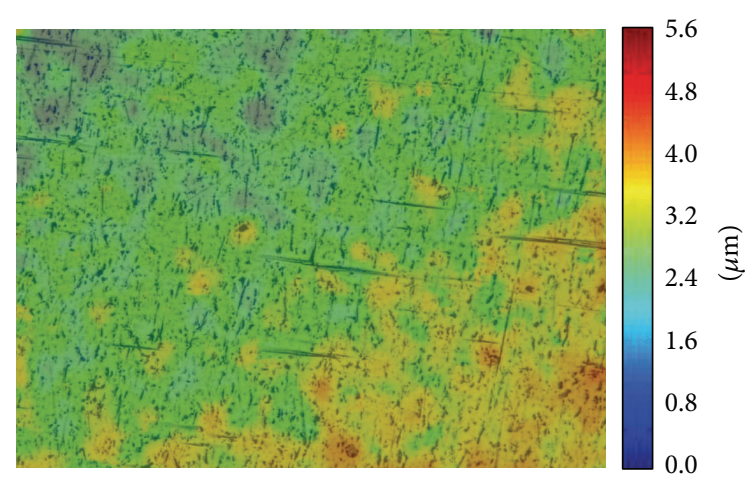

(f)

FIGURE 15: Depth cloud map of laser cladding specimens impacted by high speed droplets: (a) case 1, (b) case 2, (c) case 3, (d) case 4, (e) case 5, and (f) case 6 .

effect of impact. Figure 16 is surface elevation curves plotted from the data acquired from left to right along the depth cloud map. The black, red, and blue lines are in order drawn from the upper, middle, and lower portions of the data in Figure 15.

For laser cladding specimen, it is obvious that the red and black curves are significantly lower in the left part than in the right part. Meanwhile it is seen that regions in deep color are relatively deeper from the charts of Figure 15. This result is consistent with the observation, and therefore we can select data corresponding to the region to calculate the average depth of the surface after impact. Based on the calculation methods in this paper, we get the results of laser specimens. The depth of the impact area of laser cladding distribute in $0.5-1.5 \mu \mathrm{m}$. This material shows strong resistance to water erosion in such high speed droplet impact case.

As seen from Figure 17, the maximum relative depth of the $17-4 \mathrm{PH}$ specimens after being impacted is $10.6 \mu \mathrm{m}$ with the minimum depth being $7.6 \mu \mathrm{m}$. Despite the fact that the impact marks in the depth cloud map are not obvious, they have relatively large impact depth than that of laser cladding specimens. As the 17-4PH surface is not coated, the extent of surface polishing is relatively high. The impact regions appear 


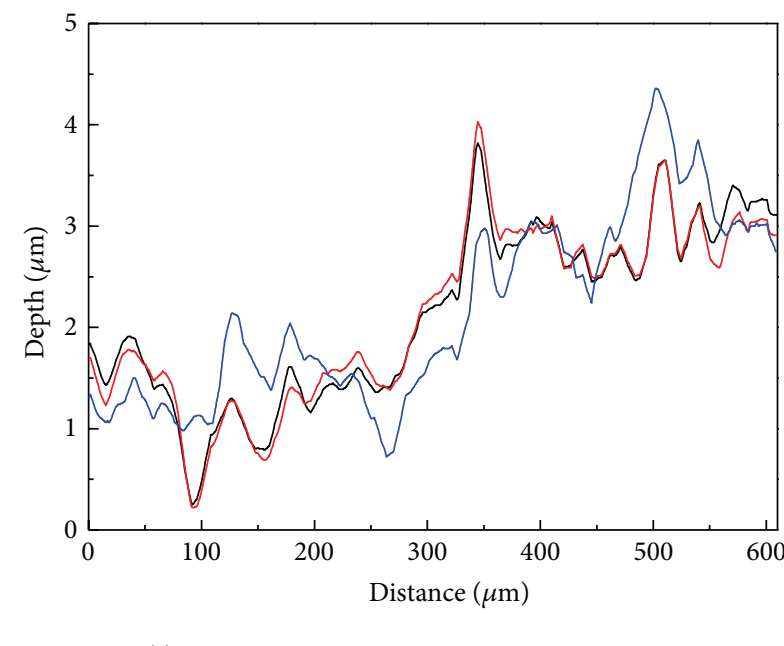

(a)

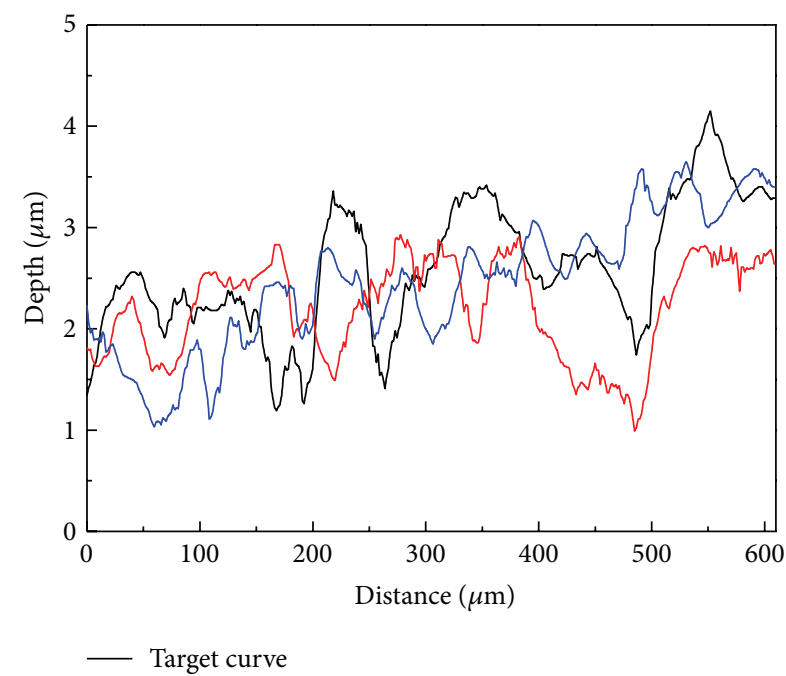

(c)

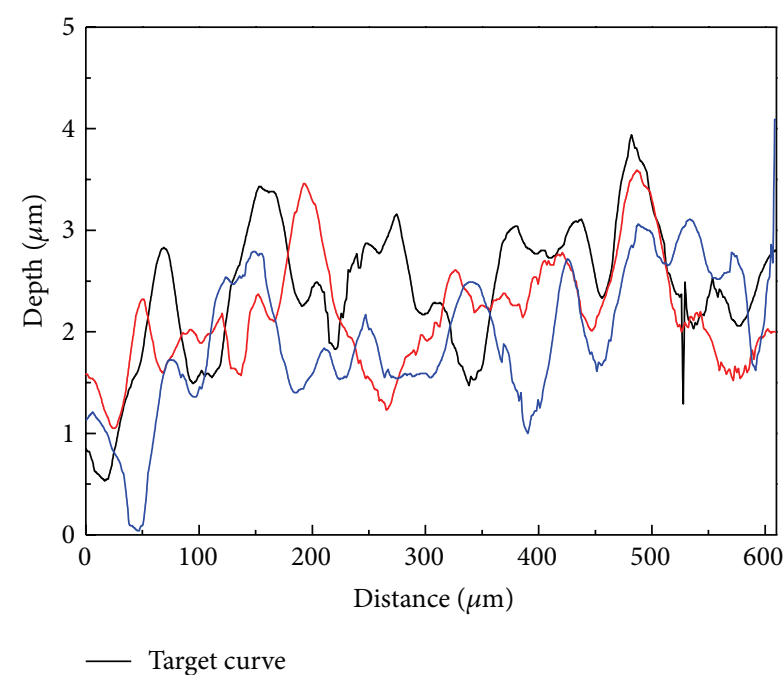

(e)

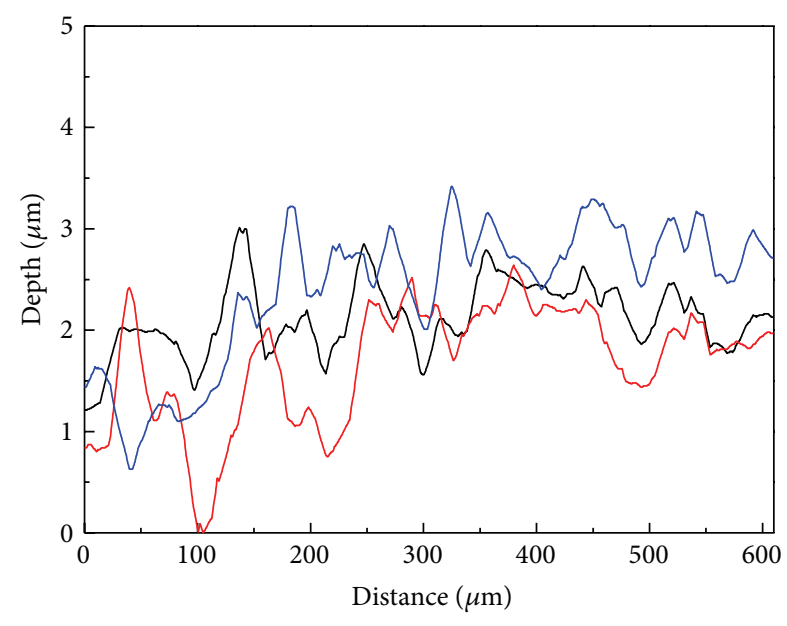

— Target curve

(b)

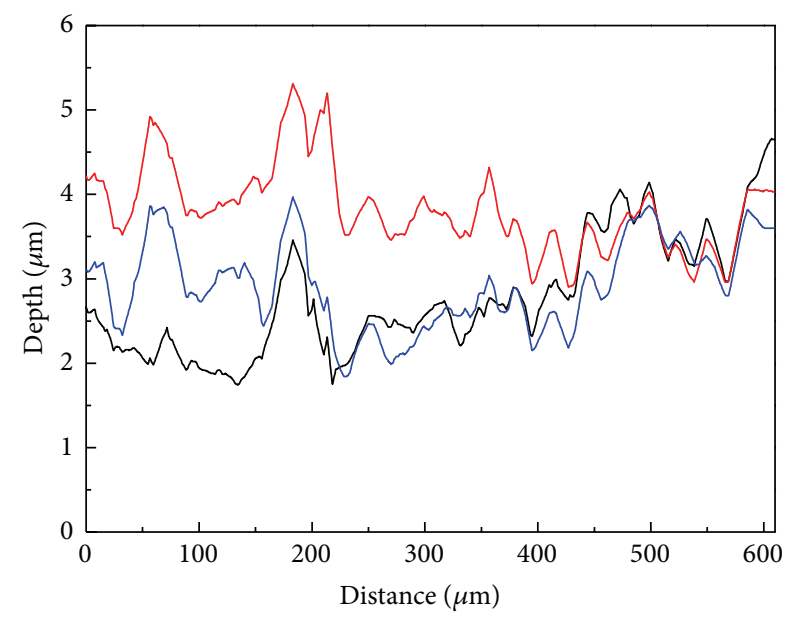

— Target curve

(d)

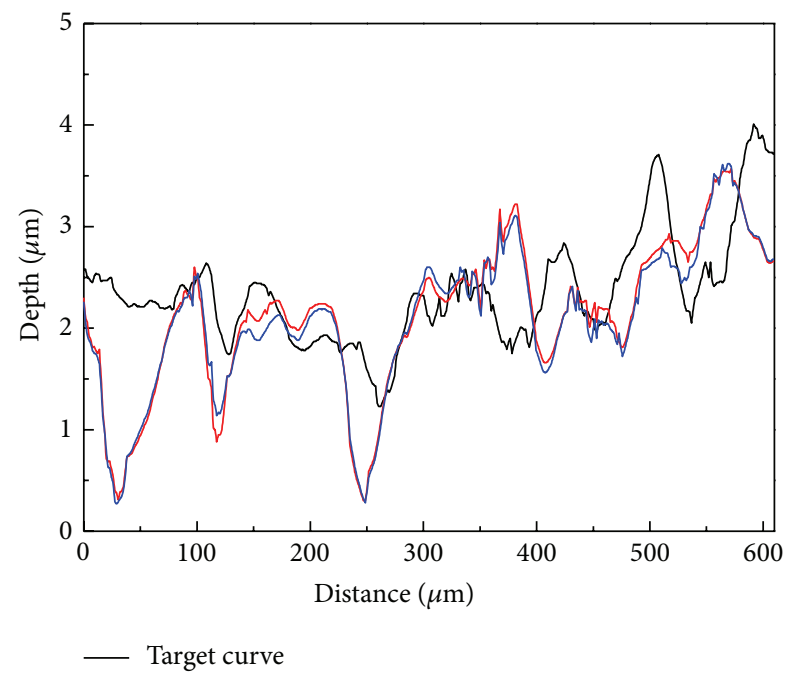

(f)

FiguRE 16: Surface elevation curves of laser cladding specimens after impact: (a) case 1, (b) case 2, (c) case 3, (d) case 4, (e) case 5, and (f) case 6. 


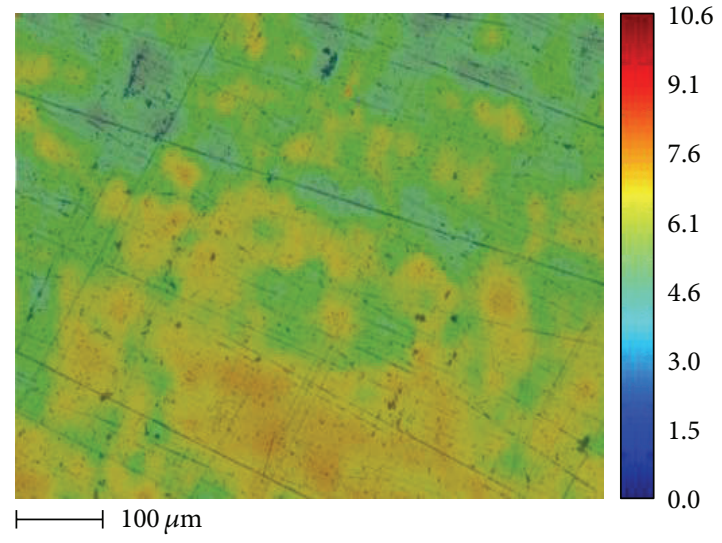

(a)

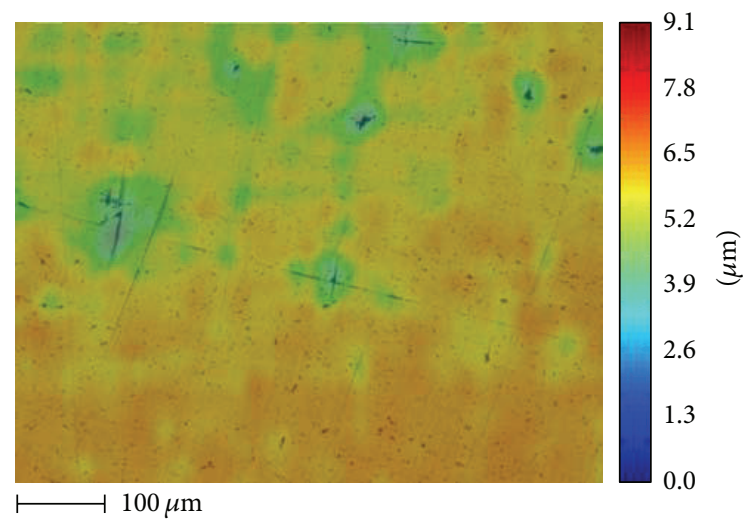

(c)

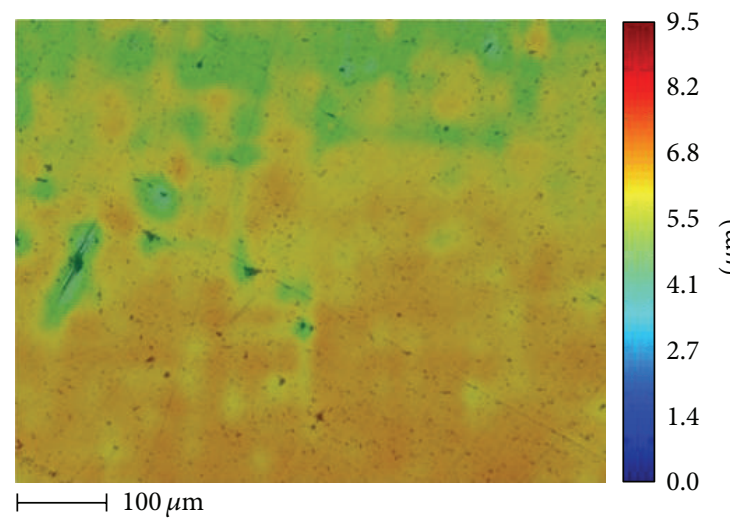

(e)

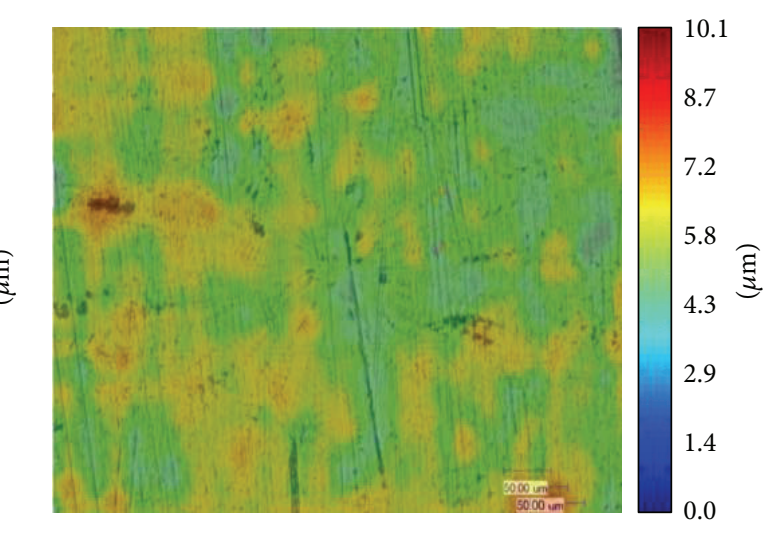

(b)

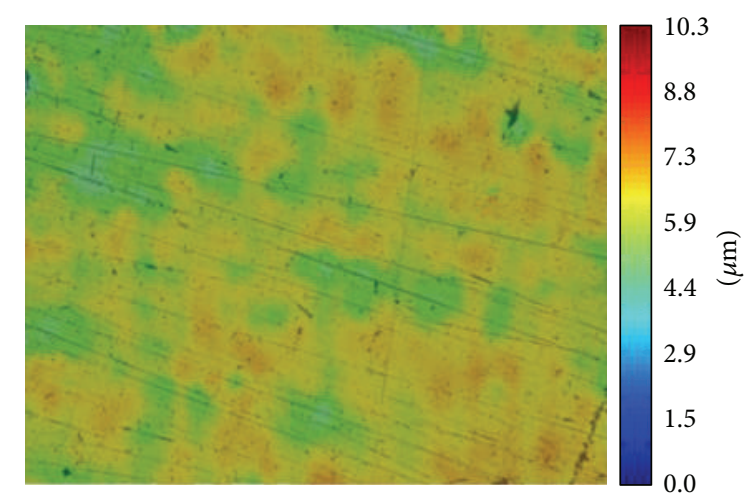

(d)

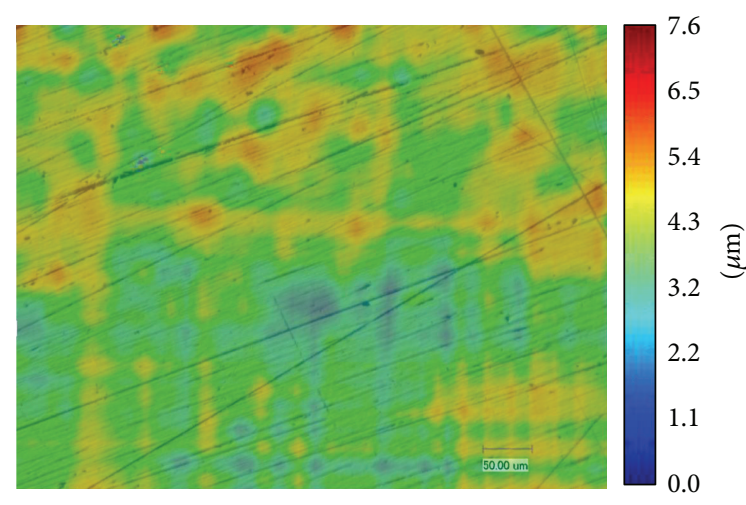

(f)

FIGURE 17: Depth cloud map of 17-4PH specimens impacted by high speed water droplets: (a) case 1, (b) case 2, (c) case 3, (d) case 4, (e) case 5 , and (f) case 6.

to be more dispersing. Through more detailed selection from the curves, the average depth of the surface after impact is obtained.

Based on the calculating methods and Figure 18, the calculated depth of the impact area of $17-4 \mathrm{PH}$ distributes in 2.5-3.5 $\mu \mathrm{m}$. By comparing the depth cloud map and the surface elevation curves of these two specimens, it can be concluded that both the depth cloud map and the surface elevation curves show that the impact depth of laser cladding specimen is much shallower.

A frequency distribution diagram that contained all results of the specimens is shown in Figure 19. The frequency distribution diagram is clearly indicating that the surface property of the material becomes more stable after laser cladding surface treatment. Therefore, a conclusion is reached that the laser cladding surface processing method is much 


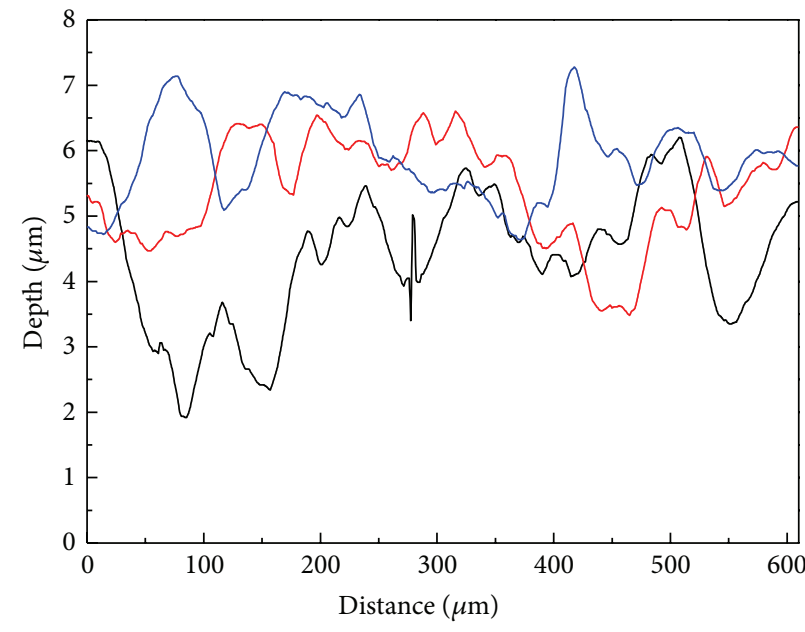

_ Target curve

(a)

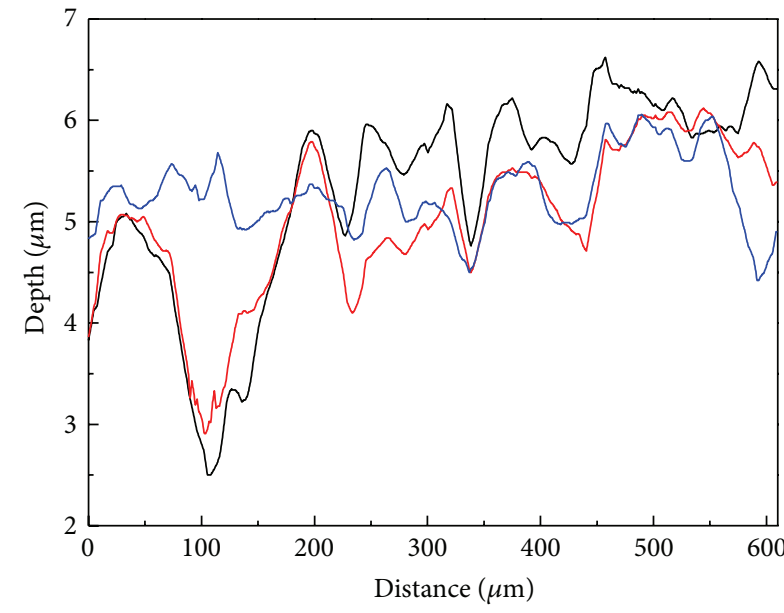

_ Target curve

(c)

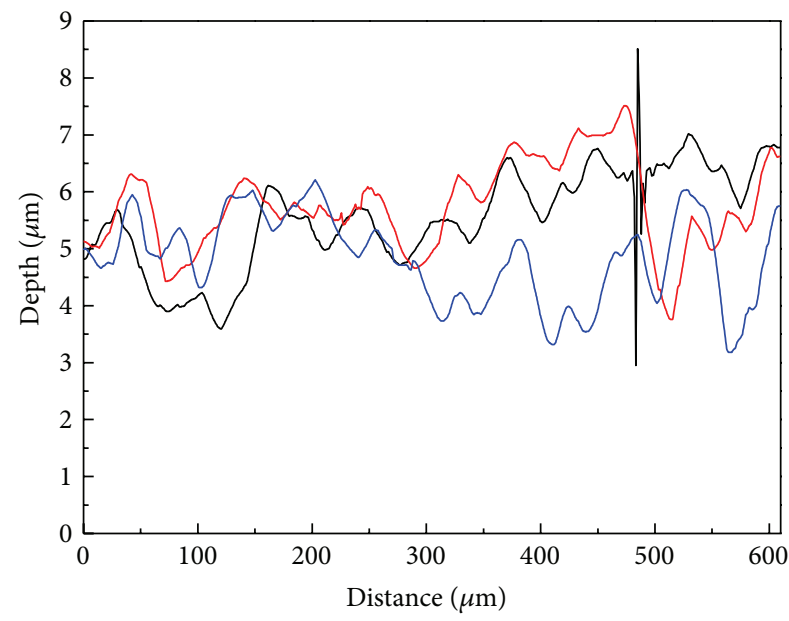

— Target curve

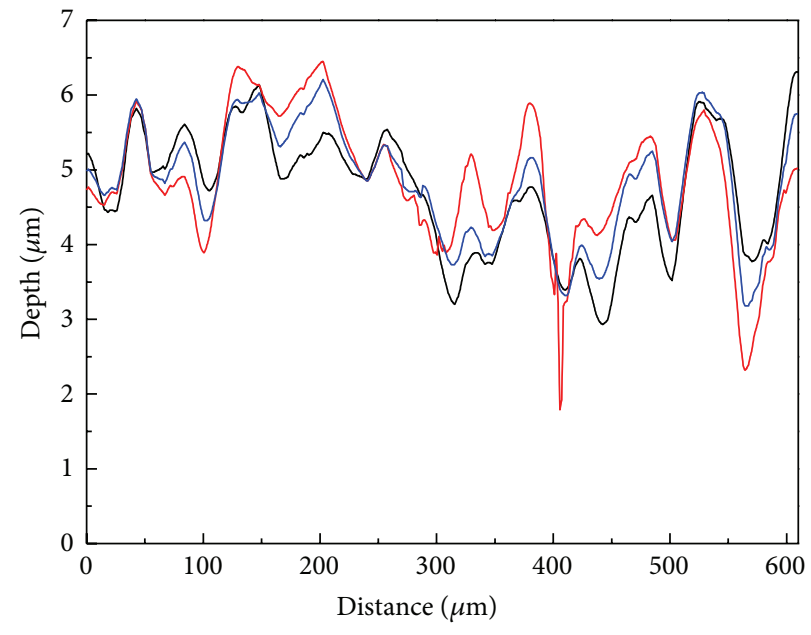

_ Target curve

(b)

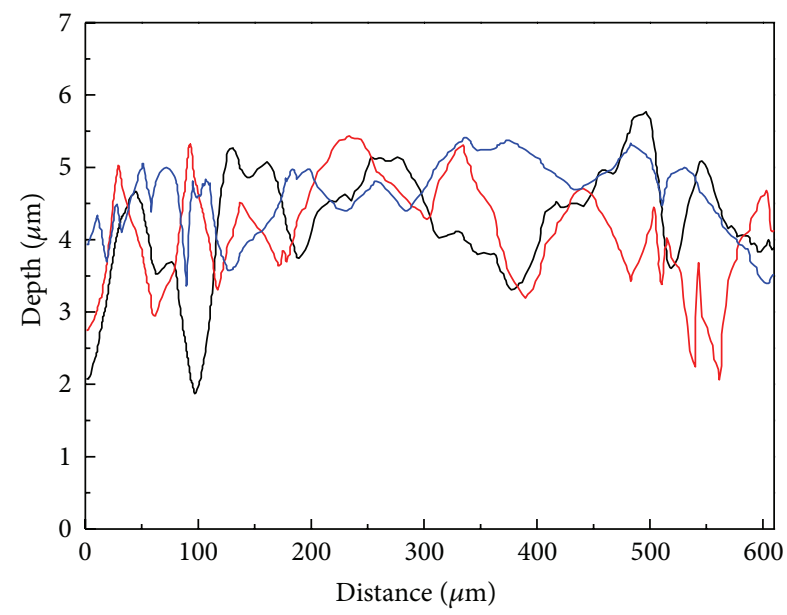

— Target curve

(d)

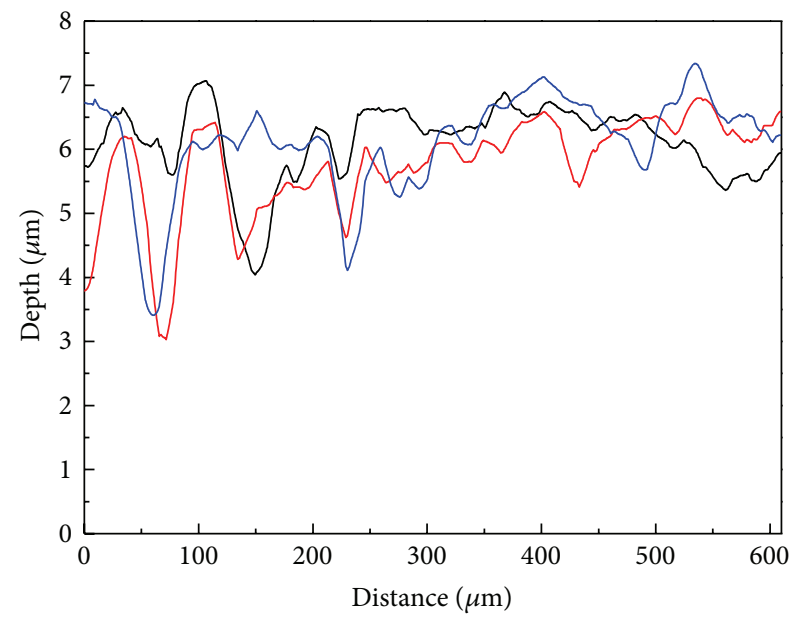

_ Target curve

(e)

(f)

FIGURE 18: Surface elevation curves of 17-4PH specimens after impact: (a) case 1, (b) case 2, (c) case 3, (d) case 4, (e) case 5, and (f) case 6. 


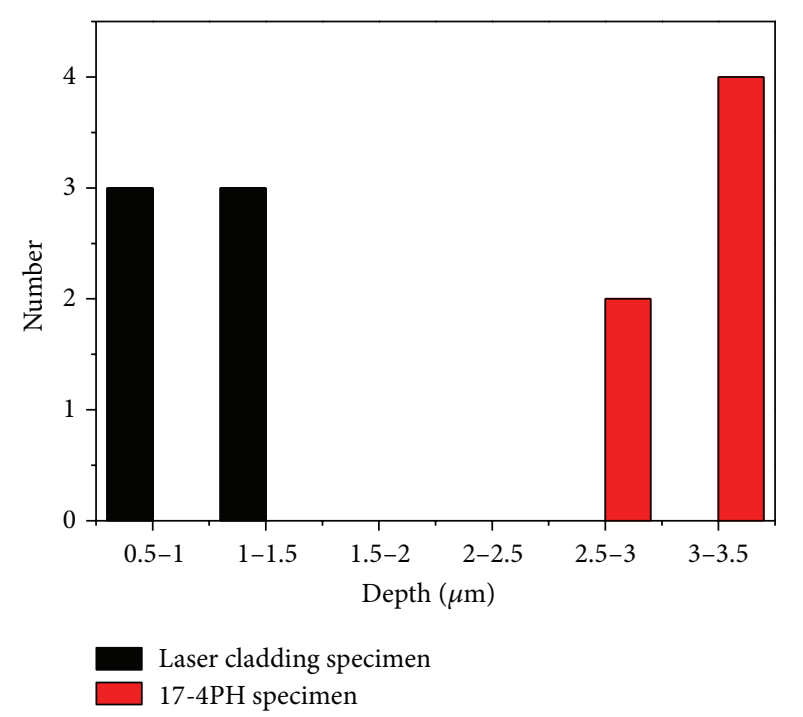

FIGURE 19: Frequency distribution diagram of impact depth.

better than ordinary blade material in terms of improving the blade material resistant to water erosion.

\section{Conclusions}

This paper compared and discussed the performance of erosion resistance between laser cladding and ordinary 17$4 \mathrm{PH}$ materials through high speed liquid-solid impact experiment. The result of the experiment showed that the average depth of the impact area for the laser cladding specimen is shallower than that of $17-4 \mathrm{PH}$ specimen, which indicates that laser cladding surface processing method is much better in terms of improving the blade material resistant to water erosion.

The accuracy and reliability of the self-designed experimental systems and computing solutions are demonstrated by carrying this test. The research method and results have realistic and guiding significance to the selection of water erosion resistant method for the final stage blade of steam turbine.

\section{Conflict of Interests}

The authors declare that there is no conflict of interests regarding the publication of this paper.

\section{References}

[1] F. J. Heymann, "Liquid impingement erosion," ASM Handbook, vol. 18, pp. 221-232, 1992.

[2] G. C. Gardner, "Events leading to erosion in the steam turbine.," Proceedings of the Institution of Mechanical Engineers, vol. 178, no. 1, pp. 593-601, 1963.

[3] R. I. Crane, "Droplet deposition in steam turbines," Proceedings of the Institution of Mechanical Engineers, Part C: Journal of
Mechanical Engineering Science, vol. 218, no. 8, pp. 859-870, 2004.

[4] J. A. Hesketh and P. J. Walker, "Effects of wetness in steam turbines," Proceedings of the Institution of Mechanical Engineers, Part C: Journal of Mechanical Engineering Science, vol. 219, no. 12, pp. 1301-1314, 2005.

[5] D. Zhang, Y. Xie, and Q. Zhou, "Study on the impact between liquid drop and elastic solid," Chinese Journal of Mechanical Engineering, vol. 39, no. 6, pp. 75-85, 2003 (Chinese).

[6] M. Ahmad, M. Casey, and N. Sürken, "Experimental assessment of droplet impact erosion resistance of steam turbine blade materials," Wear, vol. 267, no. 9-10, pp. 1605-1618, 2009.

[7] M. S. Akhtar, J. Black, and M. J. C. Swainston, "Prevention of steam turbine blade erosion using stator blade heating," Proceedings of the Institution of Mechanical Engineers, vol. 191, no. 17, pp. 355-361, 1977.

[8] D. Zhang and Y. Xie, "Numerical model for blade fatigue of liquidcorrosion in steam turbine," Proceedings of the CSEE, vol. 24, no. 10, pp. 189-192, 2004 (Chinese).

[9] M. Duraiselvam, R. Galun, S. Siegmann, V. Wesling, and B. L. Mordike, "Liquid impact erosion characteristics of martensitic stainless steel laser clad with Ni-based intermetallic composites and matrix composites," Wear, vol. 261, no. 10, pp. 1140-1149, 2006.

[10] J. S. Selvan, K. Subramanian, and A. K. Nath, "Effect of laser surface hardening on En18 (AISI 5135) steel," Journal of Materials Processing Technology, vol. 91, no. 1, pp. 29-36, 1999.

[11] J. Yao, L. Wang, Q. Zhang, F. Kong, C. Lou, and Z. Chen, "Surface laser alloying of 17-4PH stainless steel steam turbine blades," Optics \& Laser Technology, vol. 40, no. 6, pp. 838-843, 2008. 

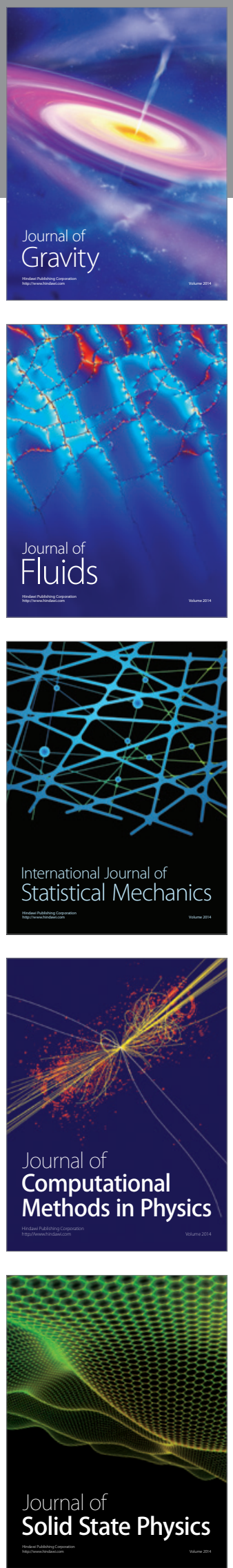

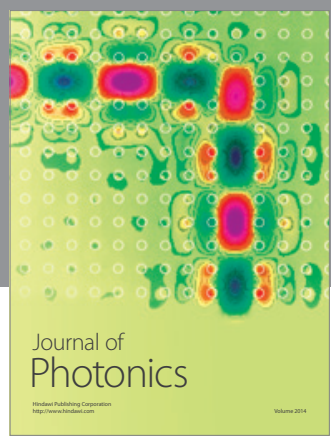

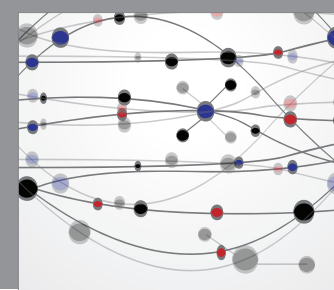

The Scientific World Journal

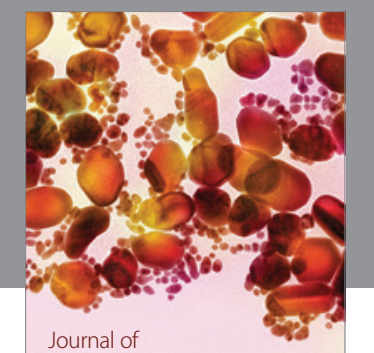

Soft Matter
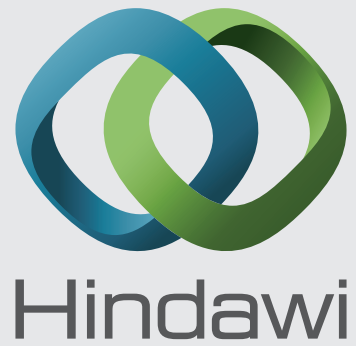

Submit your manuscripts at

http://www.hindawi.com
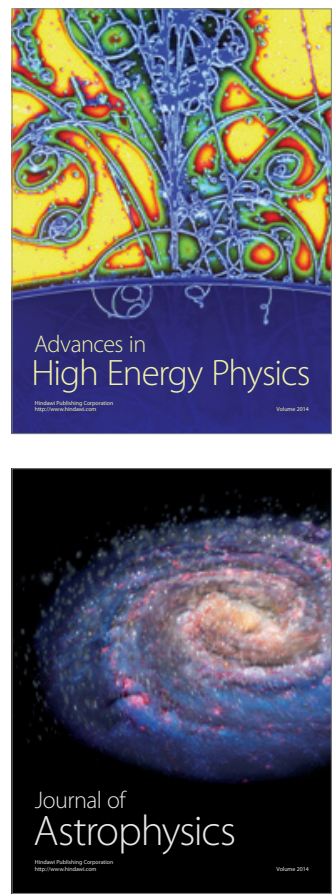
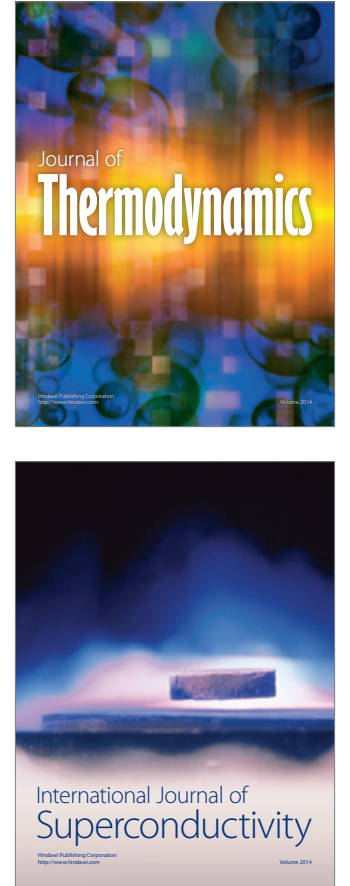
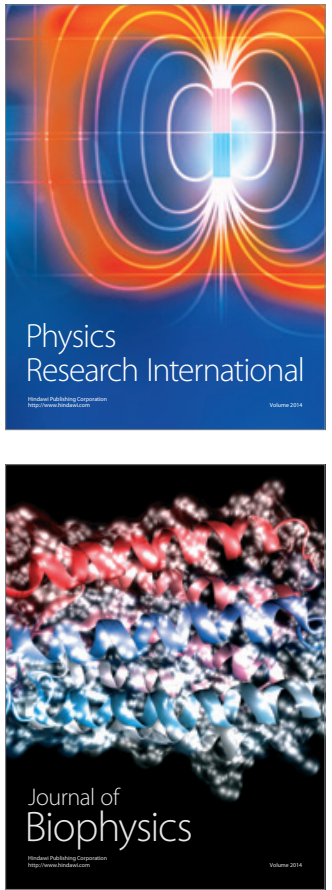
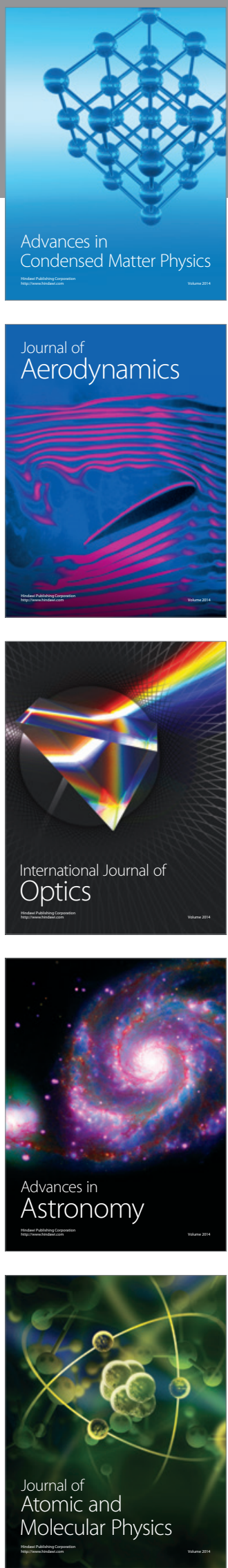